\title{
ENVIRONMENTAL STRATEGIES OF POLLUTING INDUSTRIES
}

\section{SARMENTO1, * M. DUARTE2}

\author{
${ }^{1}$ Engineering and Management Department, \\ Instituto Superior Técnico, \\ Technical University of Lisbon \\ Rua Joao Dias, 17,1400-219 Lisbon, Portugal \\ ${ }^{2}$ Accounting Department, \\ Instituto Superior de Contabilidade e Administracao \\ Av. Miguel Bombarda, 20, \\ 1069-035 Lisbon, Portugal \\ * to whom all correspondence should be addressed: \\ Fax: $+351-21-8103049$
e-mail: msc@clix.pt \\ Fax: $+351-21-8103049$
e-mail: msc@clix.pt \\ 1069-035 Lisbon, Porth
}

\begin{abstract}
Citizen concerns about environmental management practices will usually lead to public attention and legislative proposals. This paper intends to assess the behaviour of potential environmental polluting industries. In order to accomplish this objective, a survey composed of twenty-five questions was sent to large, medium and small enterprises located in Portugal. To analyse the data obtained, statistical methods - descriptive, bivariate and multivariate - were applied using SPSS 10.0 (Statistical Program for Social Sciences). The results of the present research allow the conclusion, with a confidence level of $\lambda=95 \%$, that potential polluting companies can be aggregated into five strategic groups, each one pursuing a distinct environmental strategy. Each group has specific characteristics that are reported namely in terms of identification variables and environmental strategic factors. The data analysis reveals that large environmental efforts are directly related with the company size. It also shows that most of the companies that are investing to protect the environment are those that include environmental facts (accidents) in their accounts.
\end{abstract}

KEYWORDS: environmental analysis, environmental survey, environmental statistics, ecological accidents, internalisation of externalities.

\section{INTRODUCTION}

Environment is an important political, social, cultural and economic issue affecting countries and regions worldwide. Climatic alterations, accelerated destruction of eco-systems, extinction of hundreds of species, poisoning of global food chains, soil-erosion and pollution, destruction of forests and contamination of water resources are some of the major problems facing mankind that can no longer be ignored (European Commission, 2000a). These concerns are the basis for environmentalism, an organized movement of concerned citizens and government agencies to protect and improve people's living. Intelligent environmen- 
tal strategic management in polluting industries can therefore play a vital contribution to raise our quality of life (Henriques and Sadorsky, 1996; Porter and Linde, 1995).

Considering the rising awareness of global ecological issues, consumers and ecological lobbies will increasingly require companies to accelerate implementation of cleaner production processes. They will also force governments to respect antipollution laws, in particular the polluter-payer principle, which in economic terms corresponds to the "internalisation of environmental negative externalities" (Brockhoff et al., 1999; European Commission, 2000b; Whalley and Whitehead, 1994).

Other authors suggest that environmental leadership can bring competitive advantages to industries, once environment is a public good and thus the company image is reinforced. (Klassen and McLaughlin, 1996; Roy et al.; 2001; Shrivastava, 1995). The implement of cleaner production processes also improves the market share, boosting sales and profits (Eaty and Porter, 1998; Prakash, 2001).

It is therefore important to know the strategies of polluting industries concerning the environment. This paper presents a study that intends to identify the environmental strategies pursued by Portuguese industries in relation to the management of pollution issues.

\section{OBJECTIVES}

This paper aims to contribute towards a better understanding of environmental strategies pursued by potential polluting industries. It also intends to gauge industries' environmental concerns and the manner in which such concerns are incorporated within company strategy.

For this purpose, we surveyed large-, mediumand small-size enterprises in potential polluting industries, located throughout Portugal, within seven industrial sectors that are considered to be amongst the highest polluters (National Institute of Statistics, 2000).

The following sections introduce the framework for the formulation of the survey, identify the data analysis methodology and the survey implementation, present the sample identification and determine the cause-effect relationship between the strategic factors and the companies. The research intends to identify groups of companies that share comparable environmental strategies and also discusses the links between environmental issues and corporate characteristics.

\section{THEORETICAL FRAMEWORK FOR THE FORMULATION OF THE SURVEY}

The present research on "Environmental Strategies of Polluting Industries" is based on a survey, carried out between February and November, 2001, composed of twenty-five questions. The Likert scale with five levels, from $1=$ never to $5=$ always, was used in order to assess each manager's assessment of the strategies pursued by his company.

The twenty-five questions presented in the survey are based on the field experience that the authors have as consultants and researchers in this area (Sarmento, 1999a) and in two brainstorming sessions done with a panel composed by ten leading managers from industrial companies and one expert from the Ministry of Environment. Special attention was given to the total number of questions of the inquiry (no more than twenty-five), in order to maximize the number of answers without affecting the global information to collect (Sarmento, 1999b). The decision making about the four industry identification variables, the seven strategic factors and the fourteen questions about environmental management standards ISO 14000 were selected by the brainstorming method (Sarmento, 1999a). The survey questionnaire was validated by the referred panel before starting the market research, which was done by mail.

\section{DATA ANALYSIS METHODOLOGY}

The statistical software package, SPSS 10.0, was used to analyse the survey response database. The statistical methods applied were as follows:

(1) Descriptive analysis: to determine the frequency and percentage of company identification variables and the mean value, standard deviation, and maximum and minimum values of the seven factors under consideration;

(2) Bivariate analysis, namely the Chi-square test: to test whether the survey responses could be characterised in function of industrial activity, size, location and head-office nationality of the potential polluting companies;

(3) Multivariate analysis, namely the:

- Cluster analysis: to determine homoge- 

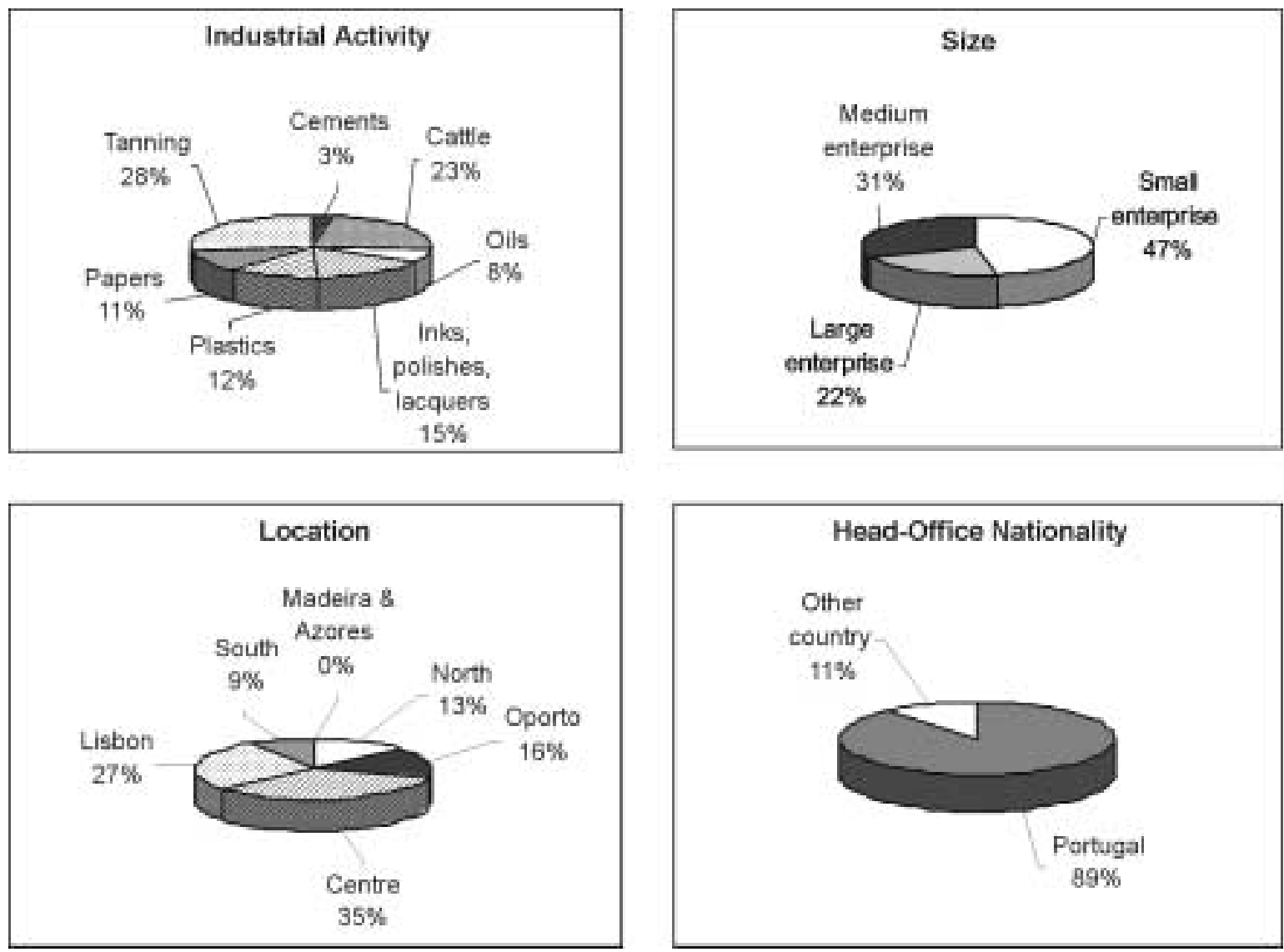

Figure 1. Industrial activity, size, location and head-office of potential polluting companies

nous groups, whereby each element of a group is more similar to the other elements of that group than to the elements of any other group;

- One-way analysis of variance: to check whether there are significant differences within the groups identified via cluster analysis and to characterise each group.

The research was based on a 520 survey questionnaires that were sent by post to potential polluting companies in Portugal (National Institute of Statistics, 2000). In order to calculate the size (n) of the adequate sample of a finite population, which guarantees a confidence level $(\lambda)$ and a precision level (D) for the population proportion (p), the following formula (1) was used:

$$
n=\frac{p \times(1-p)}{\left[D /\left(z_{a / 2}\right)\right]^{2}+[p \times(1-p)] / N}
$$

For a precision level of $\mathrm{D}= \pm 5 \%$ and a confidence level of $\lambda=95 \%$, the normal distribution has the value $\mathrm{z}_{\mathrm{a} / 2}=1.96$. In the worst-case scenario, where dispersion is at a maximum, the proportion is $p=0.5$. As a result, the sample should have the size of $n=100$ surveys. In order to build the database we received 119 survey responses, however 19 were rejected because they had several missing values. The response rate to the survey was $19.2 \%$.

\section{Identification of the sample and strategic factors}

The company's identification - industrial activity, size, location in Portugal and head-office nationality - is outlined in the Figure 1. According to the statistical study, these results are correct for the population assuming a confidence level of $\lambda=95 \%$.

The mean value and standard deviation of the seven strategic factors are presented in Table 1. 
Table 1. Mean value and standard deviation of the factors

\begin{tabular}{|l|l|c|c|}
\hline \multicolumn{2}{|l|}{ Strategic Factors } & Mean Value & Std. Dev. \\
\hline 1 & The company has environmental concerns & 4.3 & 0.64 \\
\hline 2 & The company has permanent environmental concerns & 3.9 & 0.93 \\
\hline 3 & The company has already caused a polluting accident & 1.9 & 1.09 \\
\hline 4 & The company makes investments to protect the environment & 3.5 & 1.12 \\
\hline 5 & The company includes environmental facts in its accounts & 2.5 & 1.16 \\
\hline 6 & $\begin{array}{l}\text { The company has financial investments that may be damaged } \\
\text { by ecological accidents }\end{array}$ & 1.6 & 0.61 \\
\hline 7 & The company has insurance policies against possible ecological accidents & 2.0 & 1.01 \\
\hline
\end{tabular}

Table 2. Frequency percentage per strategic factor

\begin{tabular}{|c|c|c|c|c|c|}
\hline $\begin{array}{c}\text { Strategic } \\
\text { Factors }\end{array}$ & $\begin{array}{c}\text { Nothing } \\
1\end{array}$ & $\begin{array}{c}\text { Little } \\
2\end{array}$ & $\begin{array}{c}\text { Reasonably } \\
\mathbf{3}\end{array}$ & $\begin{array}{c}\text { Much } \\
4\end{array}$ & $\begin{array}{c}\text { Strongly } \\
5\end{array}$ \\
\hline 1 & $2 \%$ & $2 \%$ & $8 \%$ & $50 \%$ & $38 \%$ \\
\hline 2 & $4 \%$ & $2 \%$ & $15 \%$ & $44 \%$ & $35 \%$ \\
\hline 3 & $35 \%$ & $20 \%$ & $22 \%$ & $23 \%$ & $0 \%$ \\
\hline 4 & $8 \%$ & $0 \%$ & $42 \%$ & $23 \%$ & $27 \%$ \\
\hline 5 & $23 \%$ & $26 \%$ & $35 \%$ & $8 \%$ & $8 \%$ \\
\hline 6 & $85 \%$ & $6 \%$ & $5 \%$ & $4 \%$ & $0 \%$ \\
\hline 7 & $39 \%$ & $36 \%$ & $19 \%$ & $2 \%$ & $4 \%$ \\
\hline
\end{tabular}

"The company has environmental concerns" $\left(x_{m}=4.3 ; s=0.64\right)$ is the highest mean value $\left(x_{m}\right)$. The lowest mean value and standard deviation (s) were obtained in "the company has financial investments that may be damaged by ecological accidents" ( $\left.\mathrm{x}_{\mathrm{m}}=1.6 ; \mathrm{s}=0.61\right)$.

The frequency percentage for each of the seven strategic factors is shown in Table 2.

"The company has financial investments that may be damaged by ecological accidents" has the highest percentage value $85 \%$ in level 1 .

The lowest percentage, of $0 \%$, occurred in three strategic factors: "the company has already caused a polluting accident", in level 5; "the company has made investments in order to protect the environment", in level 2 and "the company has financial investments that may be damaged by ecological accidents", in level 5.

Figure 2 shows that polluting accidents occurred mainly in the soil - 20\% ("soil" - 12\% and "soil and water" - 8\%). $35 \%$ of surveyed companies had never suffered a polluting accident.

\section{Relationship between the industry identification and survey responses}

To determine whether a company strategy is dependent or independent of the activity, size, location and head-office nationality, the Chisquare test was used. Without detailing the theoretical aspects of this statistical method, it is relevant to emphasize that it compares the observed and expected frequencies of two variables of the sample and checks whether it is possible to accept the hypothesis of independence between these variables within the population.

According to Newbold (1995) the comparison between Pearson and alpha significances, makes possible to accept or reject the hypothesis. If Pearson significance is less than 5\% there are no

\section{Polluting Accident}

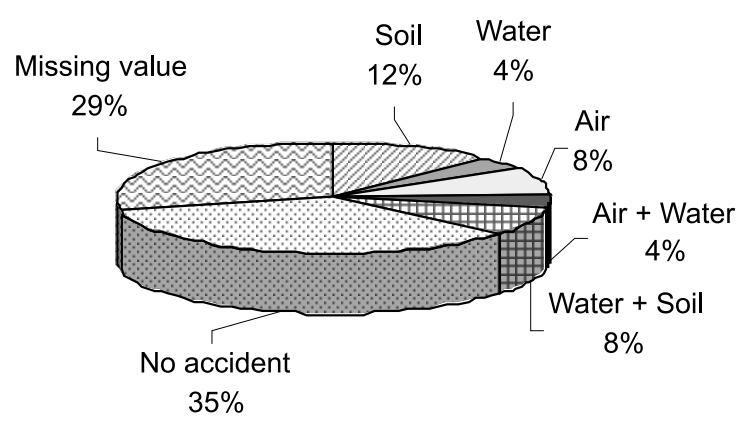

Figure 2. Percentage of polluting accidents 
Table 3. Relationship between factors and industry identification

\begin{tabular}{|c|c|l|c|l|c|l|l|l|}
\hline \multirow{2}{*}{$\begin{array}{c}\text { Strategic } \\
\text { Factors }\end{array}$} & \multicolumn{2}{|c|}{ Activity } & \multicolumn{2}{c|}{ Size } & \multicolumn{2}{c|}{ Location } & \multicolumn{2}{c|}{ Head-Office Nationality } \\
\cline { 2 - 9 } & $\begin{array}{c}\text { Pearson } \\
\text { Asymp. } \\
\text { Signif. }\end{array}$ & Conclusion & $\begin{array}{c}\text { Pearson } \\
\text { Asymp. } \\
\text { Signif. }\end{array}$ & Conclusion & $\begin{array}{c}\text { Pearson } \\
\text { Asymp. } \\
\text { Signif. }\end{array}$ & Conclusion & $\begin{array}{c}\text { Pearson } \\
\text { Asymp. } \\
\text { Signif. }\end{array}$ & Conclusion \\
\hline 1 & 0.001 & Dependent & 0.031 & Dependent & 0.381 & Independent & 0.006 & Dependent \\
\hline 2 & 0.010 & Dependent & 0.224 & Independent & 0.099 & Independent & 0.362 & Independent \\
\hline 3 & 0.852 & Independent & 0.673 & Independent & 0.145 & Independent & 0.427 & Independent \\
\hline 4 & 0.248 & Independent & 0.075 & Independent & 0.863 & Independent & 0.001 & Dependent \\
\hline 5 & 0.043 & Dependent & 0.808 & Independent & 0.905 & Independent & 0.023 & Dependent \\
\hline 6 & 0.064 & Independent & 0.561 & Independent & 0.210 & Independent & 0.548 & Independent \\
\hline 7 & 0.023 & Dependent & 0.090 & Independent & 0.301 & Independent & 0.776 & Independent \\
\hline
\end{tabular}

Table 4. Percentage of dependent / independent responses

\begin{tabular}{|l|c|c|}
\hline Industry Identification & Dependent Factor & Independent Factor \\
\hline Activity & $57 \%$ & $43 \%$ \\
\hline Size & $14 \%$ & $86 \%$ \\
\hline Location & $0 \%$ & $100 \%$ \\
\hline Head-Office Nationality & $43 \%$ & $57 \%$ \\
\hline
\end{tabular}

reasons to accept the independence between these variables.

In Table 3 the results and conclusions of the Chisquare test applied to factors and to industry identification variables are shown.

The opinions expressed in "the company has already caused any polluting accident" and in "the company has financial investments that may be damaged by ecological accidents" are always independent of industrial activity, size, location and head-office nationality.

"The company has environmental concerns" is dependent on industrial activity, size and headoffice nationality.

Table 4 reveals that managers' environmental strategies are dependent on the industrial activity in $57 \%$, head office nationality in $43 \%$ and company size in $14 \%$. Environmental strategies are totally independent of company's location.

\section{Determination of groups}

Cluster analysis was used in order to identify groups of companies sharing relatively homogeneous environmental strategies (Sarmento, 1997). On this basis, companies within any one group are implementing similar strategies, distinct from those used by companies belonging to other groups.

The used cluster analysis attempts to identify groups of companies based on seven strategic factors, using a specific algorithm which definition is the following: Squared Euclidean distance for the similarity measure and the Ward method for clustering.

This analysis allows the conclusion that there are five strategic groups that aggregate the following number of companies:

- Group 1: 24 companies

- Group 2: 4 companies

- Group 3: 20 companies

- Group 4: 20 companies

- Group 5: 32 companies

The evolution of the companies' aggregation is outlined in the grouping tree shown in Figure 3.

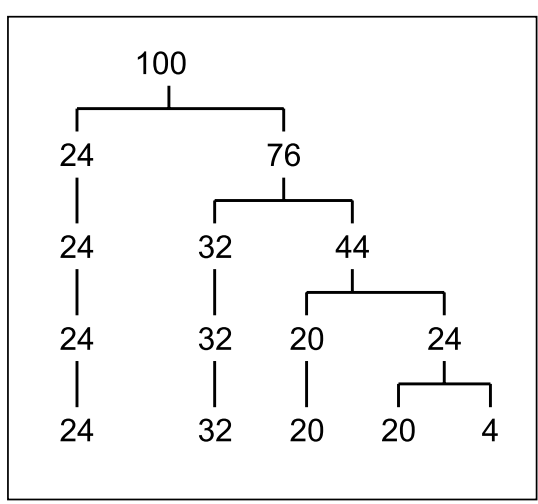

Figure 3. Grouping tree using Ward method 
Table 5. Mean values of factors for each group

\begin{tabular}{|c|l|c|c|c|c|c|c|}
\hline \multicolumn{2}{|c|}{ Strategic Factors } & Group 1 & Group 2 & Group 3 & Group 4 & Group 5 & Total \\
\cline { 2 - 7 } 1 & 24 cases & 4 cases & 20 cases & 20 cases & 32 cases & 100 cases \\
\hline $\begin{array}{l}\text { The company has environmental } \\
\text { concerns }\end{array}$ & 4.7 & 5.0 & 4.0 & 4.6 & 4.0 & 4.3 \\
\hline $\begin{array}{l}\text { The company has permanent } \\
\text { environmental concerns }\end{array}$ & 4.7 & 5.0 & 4.0 & 4.4 & 2.2 & 3.9 \\
\hline 4 & $\begin{array}{l}\text { The company has already caused } \\
\text { a polluting accident }\end{array}$ & 3.5 & 2.8 & 1.3 & 1.2 & 1.1 & 1.9 \\
\hline $\begin{array}{l}\text { The company makes investments } \\
\text { to protect the environment }\end{array}$ & 4.7 & 5.0 & 2.6 & 4.0 & 2.4 & 3.5 \\
\hline 5 & $\begin{array}{l}\text { The company includes environ- } \\
\text { mental facts in its accounts }\end{array}$ & 2.8 & 2.0 & 2.8 & 4.0 & 1.3 & 2.5 \\
\hline $\begin{array}{l}\text { The company has financial } \\
\text { investments that may be } \\
\text { damaged by ecological accidents }\end{array}$ & 1.5 & 2.6 & 1.4 & 1.2 & 1.3 & 1.6 \\
\hline 7 & $\begin{array}{l}\text { The company has insurance } \\
\text { policies against possible } \\
\text { ecological accidents }\end{array}$ & 1.8 & 5.0 & 3.0 & 1.8 & 1.2 & 2.0 \\
\hline
\end{tabular}

The discriminant analysis demonstrates that $100 \%$ of assembled companies are correctly classified in the five groups.

\section{Validation of the five strategic groups}

To validate and characterize the five groups identified in the cluster analysis, one-way analysis of variance was used.

The present objective is to apply statistic methods to strategic decision making and the theoretical details are presented by Sarmento (1999b). All the steps required for applying this method were accomplished, considering the significance level $\mathrm{a}=5 \%$, whereby it can conclude that there are five different groups.

The mean values of the factors for each group are displayed in Table 5.

Group 2 presents the maximum mean value $\left(\mathrm{x}_{\mathrm{m}}=5.0\right)$ in four factors: "the company has environmental concerns", "the company has permanent environmental concerns", "the company makes investments to protect the environment" and "the company has insurance policies against possible ecological accidents".

Nevertheless, "The company has already caused a polluting accident" has the minimum mean value $\left(\mathrm{x}_{\mathrm{m}}=1.1\right)$ in group 5 .

To confirm this conclusion we apply the Scheffé test, whereby for each one of the seven factors, each of the five groups is significantly different from the others (Sarmento, 1999b).

Although every factor differentiates the groups, there is a decreasing order of differentiation, given by $\mathrm{F}$ test (Table 6).

The most and the least differentiating factor are "the company has already caused a polluting accident" and the "the company has financial investments that may be damaged by ecological accidents", respectively.

In fact, the F and Scheffé tests, as well as the mean values of factors per group are crucial for defining the environmental strategies implemented in each group of industries.

Table 7 shows the activity, size, location and head-office nationality for each group.

\section{Characterization of the environmental strategic groups}

As showed in previous section, the polluting industries under investigation can be aggregated into five environmental strategic groups. Each 
Table 6. $\quad$ F test

\begin{tabular}{|r|l|r|}
\hline \multicolumn{2}{|l|}{ Strategic Factors } & F Test \\
\hline 1 & The company has environmental concerns & 5.587 \\
\hline 2 & The company has permanent environmental concerns & 5.646 \\
\hline 3 & The company has already caused a polluting accident & 97.089 \\
\hline 4 & The company makes investments to protect the environment & 12.748 \\
\hline 5 & The company includes environmental facts in its accounts & 30.330 \\
\hline 6 & $\begin{array}{l}\text { The company has financial investments that may be damaged by ecological } \\
\text { accidents }\end{array}$ & 4.535 \\
\hline 7 & The company has insurance policies against possible ecological accidents & 37.540 \\
\hline
\end{tabular}

Table 7. Identification variables for each group

\begin{tabular}{|c|c|c|c|c|c|c|c|}
\hline & & Group 1 & Group 2 & Group 3 & Group 4 & Group 5 & Total \\
\hline Identifica & tion Characteristics of & 24 cases & 4 cases & 20 cases & 20 cases & 32 cases & 100 cases \\
\hline & Industries & $24 \%$ & $4 \%$ & $20 \%$ & $20 \%$ & $32 \%$ & $100.0 \%$ \\
\hline & & $\mathrm{x}_{\mathrm{m}}=3.4$ & $\mathrm{x}_{\mathrm{m}}=3.9$ & $\mathrm{x}_{\mathrm{m}}=2.7$ & $\mathrm{x}_{\mathrm{m}}=3.0$ & $\mathrm{x}_{\mathrm{m}}=1.9$ & $\mathrm{x}_{\mathrm{m}}=3.0$ \\
\hline & Oil & $29 \%$ & $25 \%$ & & & & $8 \%$ \\
\hline & $\begin{array}{l}\text { Paint, ink, polish \& } \\
\text { lacquer }\end{array}$ & $4 \%$ & & $5 \%$ & $65 \%$ & & $15 \%$ \\
\hline & Plastic & $50 \%$ & & & & & $12 \%$ \\
\hline Activity & Paper & $17 \%$ & & & $35 \%$ & & $11 \%$ \\
\hline & Tanning & & & $95 \%$ & & $28 \%$ & $28 \%$ \\
\hline & Cement & & $75 \%$ & & & & $3 \%$ \\
\hline & $\begin{array}{l}\text { Cattle (breeding, } \\
\text { conservation, slaughter) }\end{array}$ & & & & & $72 \%$ & $23 \%$ \\
\hline & Large enterprise & $50 \%$ & $100 \%$ & & $30 \%$ & & $22 \%$ \\
\hline Size & Medium enterprise & $50 \%$ & & $10 \%$ & $70 \%$ & $9 \%$ & $31 \%$ \\
\hline & Small enterprise & & & $90 \%$ & & $91 \%$ & $47 \%$ \\
\hline & North of Portugal & $25 \%$ & & $15 \%$ & & $13 \%$ & $13 \%$ \\
\hline & Oporto & $17 \%$ & & $50 \%$ & & $6 \%$ & $16 \%$ \\
\hline I s ti & Centre of Portugal & $42 \%$ & $50 \%$ & $35 \%$ & $35 \%$ & $28 \%$ & $35 \%$ \\
\hline Location & Lisbon & $17 \%$ & $25 \%$ & & $65 \%$ & $28 \%$ & $27 \%$ \\
\hline & South of Portugal & & $25 \%$ & & & $25 \%$ & $9 \%$ \\
\hline & Madeira \& Azores & & & & & & $0 \%$ \\
\hline Head-Office & Portuguese & $58 \%$ & $75 \%$ & $100 \%$ & $100 \%$ & $100 \%$ & $89 \%$ \\
\hline Nationality & Other country & $42 \%$ & $25 \%$ & & & & $11 \%$ \\
\hline
\end{tabular}

group has a distinct approach to the polluting impact on the environment, in terms of the seven factors and four identification variables.

- Group 1:

Identification characteristics: This group of industries represents $24 \%$ of the sample. It includes companies pertaining to four industrial activities, whereby oil companies repre- sent $29 \%$ of the group and plastic companies $50 \%$. Large- and medium-size enterprises represent $100 \%$ of the group. $42 \%$ of companies are located in the centre of Portugal and $42 \%$ are foreign companies.

Environmental strategies: This group has a mean value of $x_{m}=3.4$, denoting that companies have moderate concerns regarding the 
seven strategic factors.

The companies pertaining to this group have strong environmental concerns $\left(\mathrm{x}_{\mathrm{m}}=4.7\right)$ of a permanent nature $\left(\mathrm{x}_{\mathrm{m}}=4.7\right)$ and they make high investments in order to protect the environment $\left(\mathrm{x}_{\mathrm{m}}=4.7\right)$.

These companies assume that have caused several pollution accidents $\left(\mathrm{x}_{\mathrm{m}}=3.5\right)$ and sometimes they include environmental issues in their accounts $\left(\mathrm{x}_{\mathrm{m}}=2.8\right)$. Insurance policies $\left(\mathrm{x}_{\mathrm{m}}=1.8\right)$ and financial investments that may be damaged by ecological accidents $\left(\mathrm{x}_{\mathrm{m}}=1.5\right)$ are rarely made.

\section{- Group 2:}

Identification characteristics: This group of industries is the smallest of the sample representing 4\%. Among the five groups, this has the highest percentage of cement companies $75 \%$, of large enterprises $-100 \%$ and of industries located in the centre of Portugal - 50\%. Foreign companies represent $25 \%$ of the group.

Environmental strategies: This group has the highest overall mean value of $x_{m}=3.9$, expressing a profile with a profound interest in the seven strategic factors.

The companies belonging to this group have strong environmental concerns $\left(\mathrm{x}_{\mathrm{m}}=5.0\right)$ of a permanent nature $\left(\mathrm{x}_{\mathrm{m}}=5.0\right)$. They make high investments in order to protect the environment $\left(x_{m}=5.0\right)$ and also have insurance policies against accidents $\left(\mathrm{x}_{\mathrm{m}}=5.0\right)$. However the companies assume that they have already caused minor pollution accidents $\left(\mathrm{x}_{\mathrm{m}}=2.8\right)$ and also have made financial investments that may be damaged by ecological accidents $\left(x_{\mathrm{m}}=2.6\right)$. Environmental issues are only rarely included in the accounts $\left(x_{m}=2.0\right)$.

\section{- Group 3:}

Identification characteristics: This group of industries represents $20 \%$ of the total sample. Of all groups, this has the highest percentage of tanning companies - 95\%, located in Oporto $-50 \%$. All are Portuguese $-100 \%$ and $90 \%$ are small companies.

Environmental strategies: Group 3 has a mean value of $x_{m}=2.7$ which means that companies demonstrate some interest in the seven factors under investigation.

The companies pertaining to this group are highly concerned with environmental issues $\left(\mathrm{x}_{\mathrm{m}}=4.0\right)$ and have permanent concerns $\left(x_{m}=4.0\right)$. A small number have taken out ecological insurance policies $\left(\mathrm{x}_{\mathrm{m}}=3.0\right)$, include ecological facts in their accounts $\left(\mathrm{x}_{\mathrm{m}}=2.8\right)$ and have made investments to protect the environment $\left(x_{m}=2.6\right)$. These companies seldom make financial investments that may be damaged by ecological accidents $\left(\mathrm{x}_{\mathrm{m}}=1.4\right)$ and rarely suffer from polluting accidents $\left(\mathrm{x}_{\mathrm{m}}=1.3\right)$.

- Group 4:

Identification characteristics: This group of industries represents $20 \%$ of the sample. $65 \%$ are paint, ink, polish and lacquer companies. $70 \%$ are medium-size enterprises, $65 \%$ are located in Lisbon and $100 \%$ are Portuguese. Environmental strategies: This group has a mean value of $x_{m}=3.0$, expressing a moderate concern in the seven strategic factors.

The companies belonging to this group are very concerned with environmental issues $\left(x_{m}=4.6\right)$ and their concerns are of a permanent nature $\left(x_{m}=4.4\right)$. They generally include environmental facts in their accounts $\left(\mathrm{x}_{\mathrm{m}}=4.0\right)$ and have made investments to protect the environment $\left(\mathrm{x}_{\mathrm{m}}=4.0\right)$. A small number of these companies have taken out ecological insurance policies $\left(\mathrm{x}_{\mathrm{m}}=1.8\right)$. They have seldom suffered polluting accidents $\left(\mathrm{x}_{\mathrm{m}}=1.2\right)$ and seldom made financial investments that may be damaged by ecological accidents $\left(\mathrm{x}_{\mathrm{m}}=1.2\right)$.

\section{- Group 5:}

Identification characteristics: This group of companies is the largest, representing $32 \%$ of the sample. Of all groups, this has the highest percentage of cattle companies - 72\%, of small-size enterprises - $91 \%$ and $100 \%$ of companies are Portuguese, located throughout Portugal.

Environmental strategies: This group has a mean value of $x_{m}=1.9$, expressing a low-level of concern in the seven strategic factors. This group of companies make few investments in order to protect the environment $\left(\mathrm{x}_{\mathrm{m}}=2.4\right)$ and also have a low level of permanent environmental concerns $\left(\mathrm{x}_{\mathrm{m}}=2.2\right)$. However the great majority of companies do not include environmental facts in their accounts $\left(x_{m}=1.3\right)$, neither do they have any financial investments that may be damaged by ecological accidents $\left(\mathrm{x}_{\mathrm{m}}=1.3\right)$. They have very limited 
insurance policies against ecological accidents $\left(\mathrm{x}_{\mathrm{m}}=1.2\right)$ and have not caused any polluting accident $\left(\mathrm{x}_{\mathrm{m}}=1.1\right)$.

\section{CONCLUSIONS}

The main purpose of the research presented in this paper is to analyse the environmental and organisational behaviour of potential polluting companies. Strategic profiles of industries were studied on the basis of seven strategic factors and four company's identification variables.

This research was based on a survey that had 100 valid answers which were processed using the statistical software package SPSS 10.0 and the conclusions are valid for the population with a confidence level of $\lambda=95 \%$.

The companies involved in this research are moderately implementing the seven strategic factors $\left(x_{m}=3.0\right)$, however they are very concerned with the environment, given that for the factors "the company has environmental concerns" and "the company has permanent environmental concerns" mean values were $\mathrm{x}_{\mathrm{m}}=4.3$ and $\mathrm{x}_{\mathrm{m}}=3.9$ respectively. This research identifies that there are five organised groups of potential polluting companies with independent strategic profile and behaviour:

- Group 1 and 2 representing 28\% of the sample assumed that they have caused polluting accidents.

- All five groups demonstrate strong environmental concerns and four (Groups 1, 2, 3 and 4) have strong permanent concerns.

- Groups 1, 2 and 4, representing $48 \%$ of the sample, say that they invest heavily to protect the environment.

- The companies belonging to Groups 1,3 and 4 include environmental facts in their accounts.

- Groups 2 and 3, 24\% of the total, stress their involvement in insurance policies against ecological accidents.

Data analysis also reveals that most companies that are investing to protect the environment are those having caused polluting accidents (Group 1 and 2) or those that include environmental facts in their accounts (Group 4). Indeed, a large number of companies (Group 5) still consider that they have no social obligations or responsibilities. Nevertheless, companies are in general concerned with the environment, and Groups 1, 2 and 4 are implementing strategies related to preservation of the environment.

The results also suggest that large environmental efforts are positively related with company size (Group 1 and 2). Small enterprises have less environmental concerns and lower financial investments.

A large number of companies do not include environmental costs in their financial accounts.

On the basis of our knowledge of the sector and interviews with top managers, it is possible to conclude that environmental matters in Portugal are better than they were a decade ago. $15 \%$ of the companies are already implementing environmental management procedures, on the basis of ISO EN 14000 series.

The success of the implementation of the environmental management in industrial companies will give rise to a higher quality of life for citizens.

\section{REFERENCES}

Brockhoff K., Chakrabarti A.K. and Kirchgeorg M. (1999), Corporate Strategies in Environmental Management, Research Technology Management, July-August, 26-30.

Eaty D.C. and Porter M.E. (1998), Industrial Ecology and Competitiveness, Journal of Industrial Ecology, 2 , 35-43.

European Commission (2000a), Global Evaluation. The Environment in Europe: Orientations for the Future?, EC Publ., Brussels.

European Commission (2000b), Application du Principe du Polluteur-Payeur dans les États-Membres Bénéficiaires du Fonds de Cohesion, EC Publ., Brussels.

Henriques I. and Sadorsky P. (1996), The Determinants of an Environmentally Responsive Firm: an Empirical Approach, Journal of Environmental Economics and Management, 30, 381-395.

Klassen R.D. and McLaughlin C.P. (1996), The Impact of Environmental Management of Firm Performance, Management Science, 42, 1199-1214.

National Institute of Statistics (2000), Enterprises Statistics, Ed. INE, Lisbon.

Newbold P. (1995), Statistics for Business and Economics, $4^{\mathrm{a}}$ ed., Prentice Hall, New Jersey.

Porter M.E. and van der Linde C. (1995), Toward a New Conception of the Environment - Competitiveness Relationship, Journal of Economic Perspectives, 9, 97-118. 
Prakash A. (2001), Why do Firms Adopt "Beyond-Compliance" Environmental Policies, Business Strategy and the Environment, 10, 286-299.

Roy M., Boiral O. and Lagacé D. (2001), Environmental Commitment and Manufacturing Excellence: A Comparative Study within Canadian Industry, Business Strategy and the Environment, 10, 257-268.

Sarmento M. (1997), Behavior of Quality Groups Facing Key Variables, Técnica, 2, 17-27.

Sarmento M. (1999a), Total Quality Management. Ph.D. Thesis, Department of Management, Technical University of Lisbon.

Sarmento M. (1999b), On the Impact of World Expositions: the Case of Lisbon Expo'98, In: BIE Publ., Paris.

Shrivastava P. (1995), Environmental Technologies and Competitive Advantage, Strategic Management Journal, 16, $183-200$.

Whalley N. and Whitehead B. (1994), It's not Easy Being Green, Harvard Business Review, May-June, 46-52. 